\title{
DESVENdANDO A VIOLÊNCIA dOMÉSTICA CONTRA CRIANĢAS E ADOLESCENTES SOB A ÓTICA DOS OPERADORES DO DIREITO NA COMARCA DE JARDINÓPOLIS-SP
}

\author{
Eliana Mendes de Souza Teixeira Roque ${ }^{1}$ \\ Maria das Graças Carvalho Ferriani ${ }^{2}$
}

Roque EMST, Ferriani MGC. Desvendando a violência doméstica contra crianças e adolescentes sob a ótica dos operadores do direito na comarca de Jardinópolis-SP. Rev Latino-am Enfermagem 2002 maio-junho; 10(3):334-44.

Utilizando-se de uma abordagem qualitativa e considerando-a como aquela capaz de aprofundar a complexidade de fenômenos, fatos, processos particulares e específicos de grupos mais ou menos delimitados em extensão e capazes de serem atingidos intensamente, este artigo tem por objetivo identificar e analisar as percepções dos operadores do direito (promotor de justiça, assistente de promotoria, serventuários de justiça e juiz de direito) sobre os aspectos desencadeadores da violência doméstica em crianças e adolescentes. O estudo foi desenvolvido no Fórum da Comarca de Jardinópolis-SP-Brasil. Os resultados foram obtidos por meio de análise de conteúdo, modalidade temática. Os operadores do direito atribuem os aspectos desencadeadores da violência doméstica à desestruturação familiar, precárias condições socioeconômicas, instabilidade conjugal, doença mental, alcoolismo e ausência de políticas sociais às demandas.

DESCRITORES: criança maltratada, adolescente, violência na família, violência doméstica, justiça criminal

\section{UNVEILING VIOLENCE AT HOME AGAINST CHILDREN AND ADOLESCENTS UNDER THE VIEW OF LAW PROFESSIONALS IN THE MUNICIPALITY OF JARDINÓPOLIS-SP, BRAZIL}

Using a grounded qualitative and considering it as capable of expanding the complexity of phenomena, facts, particular and specific processes concerning groups fairly delimitated in extension and that can be intensively affected, this article aims at identifying and analyzing the perceptions of law professionals (prosecutors, prosecution assistants, judicial deputies and judges) concerning the aspects triggering violence against children and adolescents at home. The study was conducted at the Forum of the Municipality of Jardinópolis.- SP, Brazil The results were obtained by means of content analysis, thematic modality. Law professionals attribute the aspects that trigger violence at home to the lack of family structure, precarious social and economic conditions, unstable marriages, mental disorder, alcoholism as well as to the lack of social policies to meet social demands.

DESCRIPTORS: mistreated child, adolescent, family violence, violence at home, criminal justice

\footnotetext{
${ }^{1}$ Assistente Social do Tribunal de Justiça do Estado de São Paulo/ Bacharel em Direito, Especialista em violência doméstica, Mestre em Enfermagem em Saúde Pública; ${ }^{2}$ Professor Titular, e-mail: caroline@eerp.usp.br. Escola de Enfermagem de Ribeirão Preto, da Universidade de São Paulo, Centro Colaborador da OMS para o desenvolvimento da pesquisa em enfermagem
} 


\section{DESVENDANDO LA VIOLENGIA DOMÉSTICA CONTRA NIÑOS Y ADOLESCENTES DESDE LA OPTICA DE LOS OPERADORES DE DERECHO EN LA COMARCA DE JARDINÓPOLIS-SP, BRASIL}

Utilizando un abordaje cualitativo y considerándola como aquella capaz de profundizar en la complejidad de fenómenos, hechos, procesos particulares y específicos de grupos más o menos delimitados en extensión y capaces de ser afectados intensamente, éste artículo tiene por objetivo identificar y analizar las percepciones de los operadores de derecho (promotor de justicia, asistente de promotoría, ayudante de justicia y juez de derecho) sobre los aspectos generadores de la violencia domestica en niños y adolescentes. El estudio fue desarrollado en el Foro de la Comarca de Jardinópolis-SP, Brasil. Los resultados fueron obtenidos por medio del análisis de contenido, modalidad temática. Los operadores de derecho atribuyen los aspectos generadores de la violencia domestica a la falta de estructura familiar, precarias condiciones socioeconómicas, inestabilidad conyugal, enfermedad mental, alcoholismo y ausencia de políticas sociales a las demandas.

DESCRIPTORES: niño maltratado, adolescente, violencia en la familia, violencia doméstica, justicia criminal

\section{INTRODUÇÃO}

Iniciamos este artigo com a construção do objeto de estudo, delineando a temática escolhida a partir da nossa prática profissional como Assistente Social do Tribunal de Justiça do Estado de São Paulo, no Fórum da Comarca de Jardinópolis-São Paulo-Brasil.

$$
\text { O trabalho constitui-se, }
$$

fundamentalmente, no assessoramento à justiça da Infância e da Juventude, com subsídios de caráter científico para que medidas judiciais sejam aplicadas, objetivandose que os direitos da criança e do adolescente possam ser garantidos ou restabelecidos, quando violados. Utilizando-se de uma abordagem qualitativa onde a metodologia dá ênfase ao homem, enquanto autor e ator de sua própria história, capaz de retratar e refratar a realidade. Buscamos a compreensão qualitativa, como um "movimento totalizador que reúne a condição original do projeto futuro"(1).

A violência doméstica é uma das várias modalidades de expressão de violência que a humanidade pratica contra suas crianças $e$ adolescentes, sendo que as raízes desse fenômeno também estão associadas ao contexto histórico, social, cultural e político em que se insere e não pode ser compreendido somente como uma questão decorrente de conflitos interpessoais entre pais e filhos. Mesmo este relacionamento interpessoal, a qual configura um padrão abusivo de interação pai-mãe-filho, foi construído historicamente por pessoas que, ao fazê-lo, revelam as marcas de sua história pessoal no contexto da história socioeconômica, política e cultural da sociedade ${ }^{(2)}$.

A partir do século XVIII, escandalizava a opinião pública o número de bebês abandonados que eram deixados pelas mães à noite, nas ruas sujas, muitas vezes devorados por cães e outros animais que viviam nas proximidades ou vitimados pelas intempéries ou pela fome. Em outros casos, eram largados próximos à praia, onde acabavam afogados pela maré, ou deixados nas naves das igrejas ou às portas dos conventos, na esperança de que algum padre ou freira bondosos os alimentassem e thes conseguissem um $\operatorname{lar}^{(3)}$.

Para amenizar os sofrimentos dos enjeitados, foram criadas as rodas dos expostos, nas Santas Casa de Misericórdia, 
seguindo a tradição portuguesa. Somente a partir do século XVII, é que se encontram notícias dos expostos. No Brasil, as primeiras rodas foram instaladas em Salvador e no Rio de Janeiro, no século XVIII, o que caracteriza um problema urbano. A deposição da criança nessa roda garantia o anonimato dos genitores $^{(4)}$.

A criança que entrava pelo mecanismo da Roda passava sua existência caracterizada por uma constante circulação que a destinava a uma categoria de excluídos, marginalizados, com dificuldades quase intransponíveis para a formação de sua identidade ${ }^{(5)}$.

Discursos em jornais e revistas do final do século XIX lançavam a culpa do abandono e desproteção da criança às famílias. Na primeira metade do século $\mathrm{XX}$, os juristas apontavam, como causa do abandono, as condições econômicas da população e a desagregação familiar. Tal concepção ganha espaço no meio jurídico, começando-se a entender que caberia ao Estado implantar uma política de proteção e assistência à criança, conforme estabeleceu o decreto 16.272 , de novembro de $1923^{(6)}$.

Em 12 de outubro de 1927, o DecretoLei 17.943-A institui o primeiro Código de menores no Brasil, buscando sistematizar a ação de tutela e coerção que o Estado passa a adotar. Com tal decreto, o Brasil começa a implantar o seu sistema público de atenção às crianças e jovens em circunstâncias especialmente difíceis.

Já o Código de menores de 1979, disciplinado pela Lei 6.697 , de 10 de outubro de 1979, ofereceu assistência, proteção e vigilância a "menores" até 18 anos, cuidando de catalogar casos em que o menor pudesse estar em "situação irregular", ainda que estivesse em companhia dos pais ou responsáveis, descrevendo seis categorias: a) abandonados, b) carentes, c) em abandono eventual, d) com desvio de conduta, e) infratores, f) vítimas - (vocabulário utilizado para referenciar crianças que sofreram maustratos impostos por seus pais ou responsáveis, ou em perigo moral por se encontrarem de modo habitual, em ambiente contrário aos bons costumes, conforme art. $2^{\circ}$, II e III do Código de Menores $\left.{ }^{(7)}\right)$.

Atualmente, vige entre nós o ECA (Estatuto da Criança e do Adolescente) - Lei 8069 de 13 de julho de $1990^{(8)}$, que, revolucionando em termos doutrinários e legislativos, rompeu com a doutrina da situação irregular e adotou a doutrina da proteção integral.

A proteção integral à criança e ao adolescente representa um avanço cultural da sociedade como um todo, reconhecendo-os como parte integrante da família e da sociedade, com direito ao respeito, à dignidade, à liberdade, à opinião, à alimentação, ao estudo, dentre outros.

Com mudanças de conteúdo, método e gestão, o ECA acrescenta novos elementos às políticas públicas para a infância e juventude, com atendimento muito mais amplo, com o Estado substituindo o então assistencialismo vigente por intervenções socioeducativas baseadas no fato de crianças e adolescentes serem pessoas em desenvolvimento e cidadãos de direito, promovendo uma nova estrutura de política de promoção e defesa desses direitos baseada na descentralização político-administrativa e na participação da sociedade por meio de suas organizações representativas. O ECA é, portanto, uma legislação moderna e revolucionária em seus conceitos na letra da lei. 
Mas será que dentro dos tribunais, contando com dispositivo legal tão eficiente, a questão da violência contra crianças é plenamente contemplada?

Operadores do Direito é uma terminologia que tem sido utilizada por determinada vertente crítica do Direito para denominar os juízes, promotores e advogados cujas atuações e referências se fundamentam na perspectiva de conservação do positivismo jurídico.

Além dos advogados e do Ministério Público como operadores do direito, são os magistrados, naturalmente junto com seus auxiliares, que compõem os juízos e os tribunais, sendo que os primeiros são autorizados por lei a dirigir os processos, e os seus auxiliares desempenham importante papel na sua tramitação.

O Poder Judiciário tem a função de aplicar a lei de forma coativa, tendo-se que, numa Comarca de Primeira Instância, seu juízo responde por todos os feitos na Comarca, inclusive o Juízo de Direito da Vara da Infância e da Juventude. Assim, temos a Vara (Juiz de Direito), o Ministério Público, (Promotor de Justiça), Assistente de Promotoria, o Cartório (Escrivão - diretor, Escrevente, Oficial de Justiça) e as Seções Técnicas (Assistente Social e Psicólogo).

A intervenção judiciária é decisiva, já que o poder judiciário reúne condições para determinar a cessação do abuso, por meio de medidas como: destituição do pátrio poder, determinação de tratamento para família abusiva, interdição de permanência e de contato com as crianças, prisão do(a) agressor(a).

A legislação brasileira tem um artigo em seu Código Penal que trata da crueldade e da exploração da criança, seja esta material, moral ou psicológica. No código penal, o mau-trato da criança, definido, pela primeira vez, como crime, em 1927, está descrito no capítulo III Da Periclitação da vida e da saúde.

Diante dessas questões, temos como pressuposto que a violência na família vem sendo historicamente tratada pela sociedade, de forma a banalizar as suas características específicas. O Tribunal de Justiça, ao refletir esse senso comum, torna-se também banalizador dessa questão e, quando se preocupa em responder aos trâmites da lei, no que se refere apenas ao agressor, pode reproduzir, mais uma vez, a violência contra criança e o adolescente.

Portanto, interessou-nos ter, como objetivo da pesquisa, identificar e analisar as percepções dos operadores do direito (promotor de justiça, assistente de promotoria, serventuários de justiça e juiz de direito) sobre os aspectos desencadeadores da violência doméstica em crianças e adolescentes.

\section{PERCURSO METODOLÓGICO}

O desenho metodológico adotado nesta pesquisa é de natureza qualitativa. A opção por essa abordagem baseia-se no interesse em compreender a complexidade de um fenômeno que decididamente não se limita a dados estatísticos.

Entende-se também que, para apreender a percepção/atuação dos operadores do direito sobre os casos de violência na família que chegam ao Fórum de Justiça e o grau de resolubilidade, é necessário tal abordagem, compreendendo a pesquisa qualitativa como sendo aquela capaz de 
"incorporar a questão do significado e da intencionalidade como inerentes aos atos, às relações e às estruturas sociais, estas últimas tomadas tanto no seu advento quanto na sua transformação como construção humana significativa $^{(1)}$.

Este estudo foi realizado no Fórum da Comarca de Jardinópolis-SP Brasil, com operadores do direito investidos ou não de cargos com poder de decisão judicial.

A cidade de Jardinópolis, localizada no Estado de São Paulo, é constituída por uma população de 34.111 habitantes, numa área de 552 Km. Limita-se com Ribeirão Preto, Brodósqui, Sertãozinho, Batatais e Sales de Oliveira.

A população é de baixa renda, sendo que a maioria trabalha na área rural, vivendo, aproximadamente, com um salário mínimo mensal e há desempregados.

Para delinear a percepção dos operadores do direito acerca da violência doméstica, optamos pelas técnicas de entrevista semi-estruturada e observação participante.

As entrevistas foram gravadas, após obter-se a aquiescência do entrevistado e, posteriormente, transcritas. A questão norteadora foi com base na experiência do operador de direito e como ele percebe a violência doméstica, por maus-tratos, abusos sexuais e a negligência cometidos contra crianças e adolescentes.

Para completar as entrevistas, fizemos a observação participante, utilizando-nos do diário de campo para anotações dos dados observados, informações, questionamentos.

Foram realizadas entrevistas com alguns profissionais que trabalham no Fórum da comarca de Vara Única, ou seja: 1 Promotor de Justiça, 1 Assistente de Promotoria, 4 Serventuários de Justiça e 1 Juiz de Direito.

Em relação aos critérios de inclusão, foi estabelecido ter mais de um ano de exercício de suas funções no Fórum e consentir em participar da pesquisa através da assinatura do Termo de Consentimento Livre e Esclarecido, e a aprovação pelo Comitê de Ética em Pesquisa da Escola de Enfermagem de Ribeirão Preto, da Universidade de São Paulo.

Para análise dos dados fundamentamos nos princípios e procedimentos da Técnica de Análise de Conteúdo, Modalidade Temática, buscaram-se os núcleos de sentido presentes no conjunto das entrevistas, tentando-se, ainda, descobrir o que está por trás dos conteúdos manifestos $^{(9)}$.

Após a leitura sugestiva das entrevistas e a localização de trechos que respondiam às questões norteadoras, observamos os núcleos de sentido das falas, após cuja análise, chegamos às seguintes temáticas:

1 - O que se entende por violência

2 - Como se explica a violência

Passaremos a apresentar as temáticas que emergiram da análise do material coletado.

O que se entende por violência

Nas entrevistas que realizamos, encontramos percepções diferenciadas, conforme pode ser constatado.

Em relação aos escreventes, há uma dificuldade de expressão, conforme verificado: Acredito que não podem ser explicados (...) são o resultado de uma coisa muito maior que a própria, que o próprio poder do adulto sobre a criança, pra falar a verdade, pelas coisas que acontecem, estas me parecem tão dantescas, tão horríveis, que acho que é o fim do mundo. É possível explicar o fim do mundo? (E4). 
Percebemos que, na fala acima, o escrevente não consegue verbalizar o seu entendimento sobre a questão por acreditar ser esta uma situação tão extrema, que associa "ao fim do mundo". Contudo, dois escreventes partilham de uma posição do senso comum explicitado pelo promotor e oficial de promotoria, quando associam violência a questões sócioeconômicas e culturais, à questão social como um todo, não avançando além de uma realidade objetiva que se apresenta no dia-a-dia de sua rotina de trabalho. (...) a dificuldade da realização, por exemplo, leva a pessoa a ter desvios de comportamento (...) seria a questão cultural, falta de uma educação tanto escolar, como familiar (E1) (...) às vezes está ligada à falta de dinheiro; as pessoas ficam irritadas, estressadas e acabam por cometer violência, bater nos filhos, agredir (E3).

As denúncias sobre a violência na família ocorrem em todas as classes sociais, dos mais ricos aos mais pobres. A única diferença está na forma de buscar ajuda, e de dar encaminhamento ao problema ${ }^{(10)}$. O que ocorre, na realidade, segundo a autora, é que, nas classes sociais abastadas, procuram-se consultórios particulares, mantendo-se sigilo sobre a situação. Nas classes menos favorecidas, busca-se ajuda nas instituições.

Assim, pode-se perceber que há uma visão reducionista do problema da violência doméstica, na medida que se associa violência a fatores excludentes e à única classe social, "classe menos favorecida".

Até alguns anos atrás, pensava-se que o mau-trato infantil era conseqüência de transtornos individuais, alcoolismo, toxicomania, ou de carências financeiras ou educativas e, segundo a literatura, chama atenção que: "A violência é um problema da sociedade social e histórico, é um fenômeno que possui raízes macroestruturais, formas de expressão conjunturais e atualização na cotidianeidade das relações interpessoais, sendo uma questão essencialmente social. Ela é polimórfica, multifacetada, encontrando-se diluída na sociedade sob o signo das mais diversas manifestações, que se interligam, interagem, alimentam-se e se fortalecem" ${ }^{(11)}$.

Pelos nossos achados, nas falas dos operadores de Direito, a questão da violência doméstica, vista sob a óptica jurídica, além de não vislumbrar o envolvimento de questões mais amplas como: o agressor, a família, a comunidade e a sociedade ou cultura, igualmente não contempla as expressões sociais da face, dessa mesma violência, não declinando, em suas falas, nenhuma perspectiva teórico-política necessária ao enfrentamento de suas manifestações. Identificamos que são unânimes em relação à demora, como pode ser observado nas seguintes falas: Desconheço quanto tempo leva para a conclusão de um feito com essa especificidades (...) não sabemos quanto tempo leva com cada um dos responsáveis, e nem quanto tempo leva para o juiz dar a sentença, desconhecemos, ainda, se, nessas questões, há maior rapidez por parte de todos aqueles que atuam no processo (...) (E1). Eu acho que tem que ter uma solução e a solução é a justiça e a justiça é muito demorada (E2). Se é urgente, no mesmo dia, ou em dois dias, nós damos os primeiros procedimentos, mas tudo vai depender da cota do promotor e da decisão do juiz, é esta que determina a questão dos prazos (...). Portanto o tempo total de duração é variado, mas posso te dizer que é sempre muito demorado, meses, até anos, dependendo do caso (E4).

O judiciário tenta resolver ou dar conta do problema legal de forma reducionista, seguindo os trâmites técnicos que o problema 
requer. Não há envolvimento humano para tentar resolver, de forma mais rápida e justa, tanto para a criança quanto para os elementos envolvidos na violência contra ela.

\section{Como se explica a violência}

Nas falas dos escreventes, oficial de promotoria, promotor e juiz, encontramos referência à questão da diversidade de fatores como explicativos de violência. Eu acho que aí tem uma série de fatores econômicos, por exemplo, a dificuldade da realização socioeconômica, por exemplo, leva a pessoa a ter desvios de comportamento (...).Outro, seria questão cultural, quando falo em questão cultural é a falta de uma educação tanto escolar, quanto familiar (E1).

O olhar sobre a violência está relacionado também com a história de vida do profissional que lida cotidianamente com essa questão. Alguns pesquisadores ressaltam que "não podemos negar a idéia de que qualquer diversidade cultural, as formas variadas de socialização, a multiplicidade de visões de mundo criam um mundo social amplamente marcado pela heterogeneidade de valores e interesses"(12). Isso pode ser evidenciado na fala do juiz, promotor e assistente de promotoria: Falta de cultura, educação, distúrbio psicológico, inversão de valores sociais, baixa renda é prevalente, falta de religiosidade, frustrações dos agentes, falta de conscientização pelos órgãos governamentais, etc (J). Trata-se de problema multifatorial, concorrendo para que o mesmo ecloda, por exemplo, a falta de educação adequada dos pais, poucos recursos econômicos, precária política de assistencialismo aos necessitados, dentre outros $(P)$. A explicação para esses casos pode estar ligada a muitos fatores como baixa renda, problemas mentais, falta de educação, entre outros, como a situação brasileira (AP).
Os depoimentos dos operadores de direito indicam que as ocorrências de violência se dão nas classes populares. Podemos inferir que isso se deve a dois fatores: maior incidência de ocorrências registradas nessas classes e a tendência de olhá-la relacionada à pobreza, a partir de seus próprios valores.

No entanto, todas as determinações sociais da violência possuem espectro muito amplo de entendimento, mas a pobreza em si não explica a violência, sendo certo, no entanto, que o pauperismo crescente da população, em função de uma política neoliberal, segrega e coloca à margem um número sempre maior de pessoas, desenhando situações de vida que podem criar/facilitar a delinqüência e o banditismo, numa economia marcadamente desempregadora, seletiva e excludente, onde um novo modelo de funcionamento sistêmico do capitalismo mundial, ou de uma nova modalidade de regime de acumulação, aprofunda o abismo entre ricos e pobres, sendo descartada a mão-de-obra menos qualificada.

O neoliberalismo, assim como a globalização, molda e posiciona. Sob sua égide, a doença, a violência, a miséria e a morte são especificidades de uma única análise.

A questão social expressa-se através de manifestações da violência, no campo intra e extrafamiliar, e na atualidade. Ninguém pode ignorar o papel importante que a violência vem desempenhando nas atividades humanas, ainda que sua condição como objeto de estudo seja muito recente.

No entanto, o selvagem regime capitalista que preside as relações sociais no Brasil pode explicar. "A família incerta e o não trabalho abrem um espaço para os grupos de ação violenta, o tráfico, o álcool e dependência das drogas"(13). 
Vale dizer que, nessa perspectiva, mudaram tanto os aspectos quantitativos como os qualitativos da violência, mudando, ainda, a representação da violência e sua percepção social.

Dessa forma, estão criadas as condições para o recrudescimento da violência, onde os supostamente "suspeitos" de cometê-la estão nas ruas, oferecendo perigo à visão da sociedade como um todo que ilumina apenas essa tipagem de violência, limitando sua abrangência e mantendo na sombra outros espaços de violência, hospitais, escolas, etc., mas, muito especialmente, as famílias.

Qualquer que seja o modelo familiar vigente nesse início de século XXI, essa família e seus componentes agressores, pai, mãe, responsável, são sujeitos construídos de relações estabelecidas num Brasil em que, a partir dos anos 80 , foi construindo um desenho de questão social que passou por uma politização das diferentes formas de desigualdade social.

Fatos como as campanhas eleitorais, a constituinte e a própria Constituição Federal promulgada, os movimentos sociais, valores ditados pela televisão, moldaram um sujeito em contexto sociocultural específico, mas dotado de distintos significados e implicações pessoais e sociais, onde todas as mudanças não eliminaram um aspecto crucial na relação do doméstico, ou seja: a violência doméstica contra criança e/ou adolescentes.

Mas por que a violência ocorre no espaço doméstico que, supostamente, estaria reservado a relações de harmonia?

Tal resposta não é tarefa fácil, principalmente pelo fato de a violência assumir uma forma totalmente própria de relação que se estabelece tanto no pessoal quanto no social, na política e no cultural, sendo, ainda, por vezes, resultante de interações sociais.

Vários estudiosos do tema, ancorados em bases filosóficas, antropológicas e até mitológicas, conferem-Ihe um caráter de existência em todas as sociedades, com uma posição de fenômeno complexo. A violência pode ser considerada decorrência da desigualdade social, podendo ser visualizada nas estruturas sociais e reconhecida como conceito multifacetário. Ela tem um caráter instrumental, ou seja, é um meio que necessita de orientação e justificação dos fins que persegue $^{(14)}$.

A violência pode ser pensada em dois planos. Num primeiro, mais genérico, ela seria decorrente da desigualdade social, podendo ser visualizada nas estruturas sociais. Dessa maneira, a forma de acesso e a má qualidade dos serviços públicos podem ser consideradas como violência estrutural ou institucional. Num segundo plano, mais explicito, existe a violência que provoca dano físico, que ataca o corpo do outro, que o coloca numa situação de passividade absoluta e falta de alternativa de ação. Nessa forma, um dos sujeitos foi anulado, não tem escolha, não existe a relação ${ }^{(14)}$.

Em comparação com temas que se referem à condição da criança e do adolescente, em situação de risco social e pessoal, a violência infantil é de maior abrangência. Porém, dentro do tema "violência", os trabalhos com enfoque sobre violência contra a criança e adolescente diminuem expressivamente.

Por meio de um levantamento bibliográfico sobre a criança e o adolescente, em situação de risco pessoal e social, observouse que, em relação à abordagem do tema violência infantil, existem pelo menos duas tendências diferentes: 
$1^{\text {a }}$ - Conseqüências orgânicas com intervenções clínicas.

$2^{\mathrm{a}}$ - Conseqüências socioeconômicas ${ }^{(15)}$.

Em ambas, a violência subjaz como elemento determinante de uma trajetória perversa e fatal percorrida por criança e adolescentes de todas as classes sociais. Uma trajetória que começa na violência em casa e progride na rua, onde se perpetua o ciclo(16-17).

O depoimento a seguir evidencia essa questão na fala do escrevente: ...a violência se apresenta também em função de um lar sem estrutura, num ambiente violento que pode ser formado por pessoas que, às vezes, foram violentadas na infância, sofreram abuso sexual, viram o pai batendo na mãe, e outros... (E3).

Na década de 90, especificamente nos seus cinco últimos anos, foram vivenciadas grandes transformações na sociedade.

Viveu-se, em todo mundo e particularmente no Brasil, um período histórico marcado por profundas mudanças que afetaram o conjunto da vida social como um todo, atingindo, como não poderia deixar de ser, as áreas de intervenção, os aportes de conhecimento, implementação e funcionalidades.

Todas essas transformações foram processadas na sociedade Brasileira com a mediação da inserção subordinada do país no sistema capitalista mundial e por particularidades da sua formação econômicosocial, com decorrências na complexidade das classes, com perda de sua dimensão, diferenciação, divisões, cortes e recomposições da classe operária tradicional, a emergência do trabalho autônomo, via terceirizaçãomicroempresas ou serviços pagos por tarefa, alterações nas hierarquias e articulações de camadas médias "tradicionais"(como a pequena burguesia urbana ou não) e o crescimento do setor de serviços, o que coloca a necessidade de reflexão sobre as classes populares, seus interesses, necessidades, organização e projeto político.

Outros fatores como problemas mentais e desequilíbrios psicológicos também são apontados pelos entrevistados como fatores explicativos para a violência, especificamente do abuso sexual. ... tem as pessoas que têm problema mental e cometem mesmo, e outros é por ser semvergonha, mas, no fundo, no fundo, todos que cometem esses tipo de abuso, o sexual em crianças, têm o desequilibrio muito grande. (E3).

O abuso sexual em crianças e adolescentes ainda permanece oculto, em geral é o que tem menor número de notificações, em comparação com as outras modalidades de violência. Esse tipo de violência geralmente ocorre no lar, o que põe em xeque o tabu de que, nesse ambiente, as crianças estariam protegidas de tal violência.

\section{CONSIDERAÇÕES FINAIS}

A presente pesquisa permitiu apreender as percepções dos operadores do direito sobre a violência doméstica cujos resultados, quanto aos seus aspectos desencadeadores, desenhou caminhos para sua compreensão a partir do foco do que é a questão social, palco privilegiado de sua encenação.

A violência, qualquer que seja ela, instaura-se por inúmeros e complexos fatores, passando desde a questão ambiental e o problema da qualidade de vida que atingem a realidade familiar, até o comprometimento das relações.

Por outro lado, a ordem jurídica compõe- 
se e é produto do viver em comunidade, constituinte precípuo de nossa cultura, cuja célula-mater é a família. A mesma sociedade que impõe regras e normas de conduta não transcende seus atos históricos nem seus ditames; especificamente, quanto à violência doméstica, foi possível confirmar nosso pressuposto de que, historicamente, ela é tratada pela sociedade de forma a banalizar as suas características específicas.

O Poder Judiciário parece-nos ser formado numa cultura com pouca capacidade de entender a sociedade e seus conflitos, além de estar fechado para discussão interna ou externa. Seus operadores, enquanto ramo do Estado, comungam e introjetam o ideário de sua possível redemocratização.

Ultrapassamos, dessa forma, a visão ingênua da realidade, para uma compreensão mais crítica, possibilitada pelo diálogo entre a teoria e os dados concretos apresentados.

Os relatos dos entrevistados demonstram uma visão limitada quanto à

\section{REFERÊNCIAS BIBLIOGRÁFICAS}

1. Minayo MCS. O desafio do conhecimento: pesquisa qualitativa em saúde. $6^{a}$ ed. São Paulo: HUCITECABRASCO; 1999.

2. Azevedo MA, Guerra VNA. Pondo os pingos nos is. Guia Prático para compreender o fenômeno: Módulo 1A/ $B$ do Telecurso de Especialização em violência doméstica contra crianças e adolescentes. São Paulo: LACRI/ IPUSP/USP; 1994.

3. Russell Wood, AJR. Fidalgos e filantropos. A Santa Casa da Misericórdia da Bahia, 1550-1755. Brasília: UNB; 1981.

4. Mesgravis LA. A Santa Casa de Misericórdia de São Paulo. [dissertation]. São Paulo (SP): Faculdade de Medicina de Ribeirão Preto/USP; 1972.

5. Marcílio ML. A lenta construção dos direitos da criança brasileira. Século XX-Tese Instrumentos Internacionais e Nacionais de Defesa e Proteção dos Direitos da Criança. Rev USP 1998; 37 (46/57):48.

6. Londoño FT. A origem do conceito menor. In: Del Priore M, organizador. História da criança no Brasil. São Paulo: Contexto; 1991. violência doméstica e à violência na sociedade, não citando, por exemplo, os aspectos psicossociais, éticos, morais, etc. Apesar de apontarem a multifatoriedade do problema, registram que ele está relacionado a uma determinada classe social, em discórdia com a literatura já mencionada. A violência acontece, também, em todas as classes sociais e envolve todos os profissionais, sejam eles liberais ou trabalhadores braçais.

Essa visão unilateral pode estar influindo na forma como tais profissionais atuam nos processos, levando-os, provavelmente, à banalização da violência infantil.

Acreditamos, ainda, que este estudo representa uma pequena contribuição para o avanço do conhecimento com relação à violência contra a criança e o adolescente, ao ultrapassar a simples descrição de fatos e desconstruir as falas dos sujeitos, trazendo luz à compreensão da realidade estudada, participando, assim, do desafio de construir o saber.

7. Cury M. Temas de direito do menor. Coordenação das curadorias de menores do Ministério Público do estado de São Paulo. São Paulo: RT; 1987.

8. Estatuto da Criança e do Adolescente. Lei no 8069 de 13 de julho de 1988. São Paulo; 1988.

9. Bardin L. Análise de conteúdo. Lisboa: Edições 70; 1977.

10. Ferrari DCA. A vitimização física e sexual na família e o papel da instituição.São Paulo: Agora; 1990. Cadernos de Psicodrama: psicodrama nas instituições.

11. Cruz Neto O, Moreira MRA. Concretização de políticas públicas em direção à prevenção da violência estrutural. Rev Ciência e Saúde Coletiva 1999; 4(1):34.

12. Kuyumjian MMM, Violência, poder e ordem social. UNB - Ser Social 2 - violência e exploração sexual contra crianças e adolescentes: Revista do Programa de PósGraduação e Política Social 1998; 2:9-36.

13. Faleiros VP. Desafios do Serviço Social na era da globalização. Rev Serviço Social \& Sociedade 1999 (61):164. 
14. Arendt A. As origens do totalitarismo. São Paulo: Companhia das Letras; 1990.

15. El-Khatib U. Quando se trata de investigar "criança e adolescentes em situação de risco pessoal e social"... Cadernos de Terapia Ocupacional UFSCAR 1998; 7(1):113.

16. Braz M, Cardoso MHCA. Em contato com a violência - os profissionais de saúde e seus pacientes vítimas de maus tratos. Rev Latino-am Enfermagem 2000 janeiro; 8(1):91-7.

17. Scherer EA, Scherer ZAP. A criança maltratada: uma revisão da literatura. Rev Latino-am Enfermagem 2000 agosto; 8(4):22-9. 